\title{
Demographic parameters of Diuraphis noxia (Hemiptera: Aphididae) and Hippodamia variegata (Coleoptera: Coccinellidae) recorded in the context of $D$. noxia infesting resistant and susceptible cultivars of wheat
}

\author{
LeILA ZANGANEH ${ }^{1}$, Hossein MADADI $^{1, *}$ and Hossein ALLAHYARI ${ }^{2}$ \\ ${ }^{1}$ Department of Plant Protection, Faculty of Agriculture, Bu-Ali Sina University, Hamedan, Iran; \\ e-mails: madadiho@gmail.com; ingot1984@gmail.com \\ ${ }^{2}$ Department of Plant Protection, College of Agriculture and Natural Resources, University of Tehran, Karaj, Iran; \\ e-mail: Allahyar@ut.ac.ir
}

\begin{abstract}
Key words. Hemiptera, Aphididae, Diuraphis noxia, Coleoptera, Coccinellidae, Hippodamia variegata, Russian wheat aphid, life
\end{abstract} table, host plant resistance

\begin{abstract}
The Russian wheat aphid (RWA), Diuraphis noxia (Kurdjumov), is a serious pest of small grains and can cause losses of about $80 \%$ in wheat yields. Chemical control is ineffective against this pest so the combined use of host plant resistance and biological control is seen as a possible better means of controlling this pest. In this study, the potential effect of Omid (resistant) and Sardari (susceptible) cultivars of wheat on life table parameters and daily fecundity of RWA and its predator, Hippodamia variegata (Goeze), were determined using the age-stage two-sex life table theory. The results indicate that the $\mathrm{r}_{\mathrm{m}}, \mathrm{R}_{0}, \lambda$, T and GRR of RWA were -0.005 \pm 0.01 day $^{-1}, 0.9 \pm 0.24$ offspring per individual, $0.99 \pm 0.01$ day $^{-1}, 21.16 \pm 1.79$ days and $13.34 \pm 2.91$ offspring on Omid and 0.159 \pm 0.01 day $^{-1}, 6.9 \pm 0.54$ offspring per individual, $1.17 \pm 0.01$ day $^{-1}, 12.14 \pm 0.26$ days and $12.73 \pm 1.22$ offspring on Sardari. The corresponding values for $H$. variegata fed on RWA reared on Omid were $0.24 \pm 0.01$ day $^{-1}, 399.35 \pm 53.01$ eggs, $^{1.27} \pm 0.01$ day $^{-1}, 24.67$ \pm 0.28 days and $544.23 \pm 75.86$ eggs and on Sardari $0.20 \pm 0.006$ day $^{-1}, 221.56 \pm 34.68$ eggs, $1.23 \pm 0.01$ day $^{-1}, 26.50 \pm 0.41$ days and $402.72 \pm 67.55$, respectively. The resistance of wheat cultivars significantly affected life table parameters and mean fecundity of RWA and $H$. variegata. Our results indicate that combining both host plant resistance and predators in the integrated pest management of RWA could result in a synergistic effect.
\end{abstract}

\section{INTRODUCTION}

The Russian wheat aphid (RWA), Diuraphis noxia (Kurdjumov) (Hemiptera: Aphididae), is a major pest of small grains, particularly wheat, barley, triticale, rye and wild grasses world-wide and a major cause of economic losses (Farid et al., 1997; Clark \& Messina, 1998; Qing Nian et al., 2009; Jimoh et al., 2013). It prefers to feed within the leaf whorl on new leaves (Macedo et al., 2003), injecting a toxin that causes leaf discoloration and distortion. Leaf rolling plays an important role in reducing the effectiveness of certain management strategies, by reducing contact with insecticides and the efficacy of biological control agents (Gutsche et al., 2009). When abundant, RWA reduces wheat yield directly (Kindler \& Hammon, 1996). Although a poor vector of plant pathogenic viruses, including barley yellow dwarf virus, barley brome mosaic and barley stripe mosaic (Damsteegt et al., 1992), it nevertheless can reduce the yield of wheat by up to $80 \%$ (Hughes \& Maywald, 1990).

It is difficult to manage RWA because it has a short life cycle and an extremely high reproductive rate (Dogimont et al., 2010). Insecticides are frequently used to suppress RWA populations but in addition to environmental pollution and risk to non-target beneficial insects, aphids can develop resistance to insecticides, which makes their control more difficult (Dogimont et al., 2010). Host plant resistance is one of the environmentally safe tactics widely used to reduce pest populations (Du Toit, 1987). The use of resistant plants may enhance or reduce the ability of natural enemies to control insect pests (Bottrell et al., 1998; Cortesero et al., 2000; Messina \& Sorenson, 2001). Resistant plants may affect the efficacy of important natural enemies of $D$. noxia (Reed et al., 1991) by increasing their accessibility to natural enemies (Messina \& Sorenson, 2001). Recent evidence indicates that host plant resistance and RWA predators or parasitoids can be effectively used in combination (e.g. Farid et al., 1997, 1998; Messina \& Sorenson, 2001).

The variegated lady beetle, Hippodamia variegata (Goeze) feeds on many insect pests such as aphids, psyllids, whiteflies and mealybugs (Franzman, 2002). This species is reported as an important natural enemy of at least 12 different species of aphids infesting a diversity of crops (Franzmann, 2002; Kontodimas \& Stathas, 2005). H. variegata is part of the natural enemy complex of RWA in Iran and plays a major role in reducing the abundance of this aphid. Therefore, understanding the tritrophic ecology of this predator helps to better control RWA in different situations.

\footnotetext{
* Corresponding author.
} 
Life table studies are fundamental to population ecology (Chi \& Yang, 2003; Zu et al., 2005). They provide a brief description of mortality, survival, development, age structure and fecundity of a cohort of animals (Chi \& Yang, 2003; Gabre et al., 2005; Zu et al., 2005; Huang \& Chi, 2011). Moreover, life table parameters are one of the best criteria for assessing the effects of different kinds of prey on predator survival and fecundity (Golizadeh \& JafariBehi, 2012). Tritrophic studies have shown that in many cases, the nutritional quality of host plants affect prey and predator life histories (Bottrell et al., 1998; Wu et al., 2010). Therefore, it is necessary to study the life table of predators fed on prey reared on different host plants. Although many studies have recorded the life tables of different species of lady beetles and aphids, there are few controlled studies on the effect of prey feeding history on the life history parameters of $H$. variegata. Moreover, most studies have used female age-specific life table to analyse the data whereas in this study age-stage two-sex life table is used. The main aim of this paper is to study the effect of resistant and susceptible cultivars of wheat on the life history and demographic parameters of RWA and $H$. variegata.

\section{MATERIAL AND METHODS}

\section{Insect and plant rearing}

Two wheat cultivars, the resistant Omid and susceptible Sardari (Kazemi et al., 2001; Najafi Mirak et al., 2004; Dolati et al., 2004) were grown in plastic pots in a greenhouse kept at $25 \pm 5^{\circ} \mathrm{C}, 55 \pm$ $10 \%$ relative humidity and a $12 \mathrm{~L}: 12 \mathrm{D}$ photoperiod (Department of Plant Protection, Faculty of Agriculture, Bu-Ali Sina University, Iran). Russian wheat aphids were collected from different parts of Hamedan province in western Iran. Wheat plants infested with $D$. noxia provided sufficient numbers of RWA for the experiments and the colonies were maintained on two cultivars of wheat for at least three generations. $H$. variegata were collected from an alfalfa field (Hamedan, Amzajerd region, $35^{\circ} 1^{\prime} \mathrm{N}, 48^{\circ} 31^{\prime} \mathrm{E}$ ) and fed by aphids reared on either the resistant or susceptible cultivar of wheat for at least three generations before starting the experiment.

\section{Life tables of $D$. noxia and $H$. variegata}

To obtain each RWA cohort, five adults were placed in cylindrical clip cages ( $30 \mathrm{~mm}$ diameter) one of which was clipped to each of the leaves of a wheat seedling. After $12 \mathrm{~h}$, all but one individual were removed leaving a single first instar nymph in each cage. Because, many of the RWA nymphs died prematurely on the resistant cultivar, the number of first instar nymphs reared on the resistant and susceptible cultivars was 202 and 100, respectively. Experimental plants were checked daily and nymphal mortality and developmental time were recorded. After reaching the adult stage, reproduction was recorded by removing the newborn nymphs daily. This procedure continued until the adult aphids died.

A similar procedure was used for studying the life table parameters of $H$. variegata. Lady beetle adults were reared separately on either $D$. noxia reared on resistant or susceptible wheat before the start of the experiment. Then, 107 and 113 newly laid eggs were collected from $H$. variegata fed on aphids of resistant and susceptible wheat seedlings, respectively. After hatching, the larvae were provided with either mixed stages of Omid- or Sardarireared aphids and as soon as they became adult they were sexed and paired randomly in ventilated Petri dishes (9-cm diameter).
An excess of aphids was provided to each pair and the number of eggs produced by each pair recorded daily. If one member of a pair (male or female) in each replicate died, the experiment was continued until the death of the last individual. All experiments were conducted under constant conditions $\left(25 \pm 1{ }^{\circ} \mathrm{C}, 60 \pm 5 \%\right.$ R.H. and a $16 \mathrm{~L}: 8 \mathrm{D}$ photoperiod).

\section{Data analysis}

Raw data were analyzed based on the age-stage, two-sex life table method (Chi \& Liu, 1985; Chi, 1988) in the software program TWOSEX-MS Chart (available at http://140.120.197.173/ Ecology/prod02.htm) (National Chung Hsing University, Taichung, Taiwan) and at http://nhsbig.inhs.uiuc.edu/wes/chi.html (Illinois Natural History Survey, Champaign-Urbana, IL) (Zu et al., 2005; Atlihan \& Chi, 2008). This method differs from traditional female-based life table analysis in including preadult mortality, variation in the developmental rate of adults and the male contribution to the demographic parameters. Moreover, because mean duration or "adult age" is generally used to construct the survival curve, this results in errors in population parameters (Chi \& Liu, 1985; Chi, 1988). The age-stage, two-sex life table is widely used in studies on parthenogenic species (He et al., 2013; Hu et al., 2014).

The most important life history parameter, i.e., intrinsic rate of increase $\left(\mathrm{r}_{\mathrm{m}}\right)$ was calculated using the Euler-Lotka equation (1),

$\sum_{x=0}^{\infty} l_{x} m_{x} e^{-r_{m}(x+1)}=1$

where, $x$ is the age of the aphid (days), $l_{x}$ is the age-specific survival rate and $m_{x}$ is the age-specific fecundity rate. Based on the age-stage two-sex life table, the values of $l_{x}$ and $m_{x}$ are calculated as:

$$
\begin{aligned}
& l_{x}=\sum_{j=1}^{k} s_{x j} \\
& m_{x}=\frac{\sum_{j=1}^{k} s_{x j} f_{x j}}{\sum_{j=1}^{k} s_{x j}}
\end{aligned}
$$

where, $k$ is the number of stages, $x=$ age, $j=$ stage, $s_{x j}$ is the agestage survival rate (Chi, 1988; Chi \& Yang, 2003).

In addition, life expectancy $\left(\mathrm{e}_{\mathrm{xj}}\right)$, mean fecundity $(\mathrm{F})$ of individual of age $\mathrm{x}$ and stage $\mathrm{y}$ and other parameters such as net reproductive rate $\left(R_{0}\right)$, finite rate of increase $(\lambda)$, T (mean generation time) and gross reproductive rate (GRR) were also calculated. Because the jackknife method provides incorrect estimates of the standard errors for $\mathrm{R}_{0}$ (Jha et al., 2012), bootstrap techniques were used to estimate uncertainty (Efron \& Tibshirani, 1993). Independent sample t-tests or non-parametric Mann-Whitney U tests

TABLE 1. Population parameters ( \pm SE) of Diuraphis noxia reared on Sadari, a susceptible and Omid, a resistant cultivar of wheat.

\begin{tabular}{lcc}
\hline \multirow{2}{*}{ Parameter (Unit) } & \multicolumn{2}{c}{ Wheat cultivar } \\
\cline { 2 - 3 } & Sardari & Omid \\
\hline $\mathrm{r}_{\mathrm{m}}$ (day $^{-1}$ ) & $0.159 \pm 0.01$ & $-0.005 \pm 0.01$ \\
$\mathrm{R}_{0}$ (offspring) $^{-1}$ ) & $6.9 \pm 0.54$ & $0.9 \pm 0.24$ \\
$\lambda$ (day $^{-1}$ ) & $1.172 \pm 0.01$ & $0.995 \pm 0.01$ \\
$\mathrm{~T}$ (day) & $12.14 \pm 0.26$ & $21.16 \pm 1.79$ \\
GRR (offspring) & $12.73 \pm 1.22$ & $13.34 \pm 2.91$ \\
\hline
\end{tabular}

$\mathrm{r}_{\mathrm{m}}$ - intrinsic rate of increase; $\mathrm{R}_{0}$ - net reproductive rate; $\lambda$ - finite rate of increase; $\mathrm{T}$ - mean generation time; GRR - gross reproductive rate. 


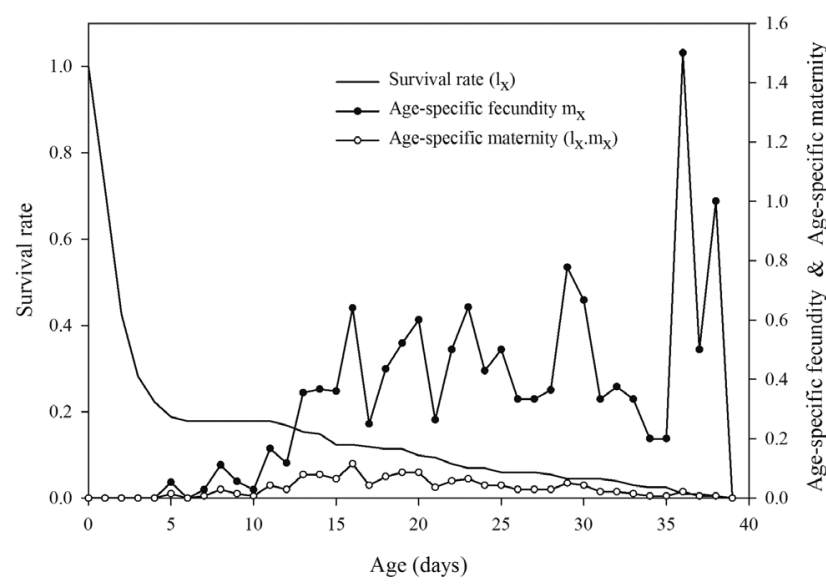

Fig. 1. Trends in time of the age-stage survival rate $\left(1_{x}\right)$, agespecific fecundity $\left(\mathrm{m}_{\mathrm{x}}\right)$ and maternity $\left(\mathrm{l}_{\mathrm{x}} \cdot \mathrm{m}_{\mathrm{x}}\right)$ rate of Diuraphis noxia reared on Omid, a resistant cultivar of wheat.

were used to compare life history parameters whenever normality assumptions were not met. In all tests, $\alpha$ was 0.05 .

\section{RESULTS}

\section{Life history parameters of RWA}

Demographic parameters of RWA reared on resistant and susceptible cultivars of wheat are given in Table 1 . The differences between the $r_{m}, R_{0}, \lambda$ and $T$ values for RWA reared on Omid and Sardari cultivars of wheat were significant (Mann-Whitney test, U Statistic $=0.000$, P-value $<0.001$ ) but not those for GRR (Mann-Whitney test, U Statistic = 491620.00, P-value = 0.516). A decreasing trend in the survival rate of RWA was recorded during the developmental period on both cultivars of wheat, but higher mortalities were recorded on the resistant than on the susceptible cultivar, especially during the early stages of development (Figs 1 and 2). The age-specific fecundity $\left(m_{x}\right)$ indicates that the number of offspring produced by an individual RWA of age $x$ on the resistant cultivar reaches its maximum value (1.5) at the end of the reproductive period (day $36)$, while on the susceptible cultivar the peak (1.024) was recorded three days after the start of reproduction. Because of the low survival rate of RWA on the resistant cultivar the net age-specific maternity, [i.e. the weighted average production of offspring by females aged $x$ each day (Carey, 1993)] was very low irrespective of the oscillations in the age-specific fecundity. However, this parameter followed the same trend as $m_{x}$ recorded on the susceptible cultivar. The female mean fecundity was $7.24 \pm 1.38$ and $8.02 \pm$ 0.53 on the resistant and susceptible cultivars, respectively.

\section{Stable age distribution of RWA}

Table 2 shows the stable age distribution (percentage). It reveals that on both cultivars adults are the most abun-

TABLE 2. Percentage of individuals in each of the developmental stages in populations of Diuraphis noxia at stable age distribution on Omid and Sardari cultivars of wheat.

\begin{tabular}{cccccc}
\hline Wheat cultivar & $1^{\text {st }}$ instar & $2^{\text {nd }}$ instar & $3^{\text {rd }}$ instar & $4^{\text {th }}$ instar & Adult \\
\hline Omid & 29.98 & 14.17 & 14.32 & 8.86 & 32.93 \\
Sardari & 27.30 & 18.22 & 13.47 & 8.36 & 32.46 \\
\hline
\end{tabular}

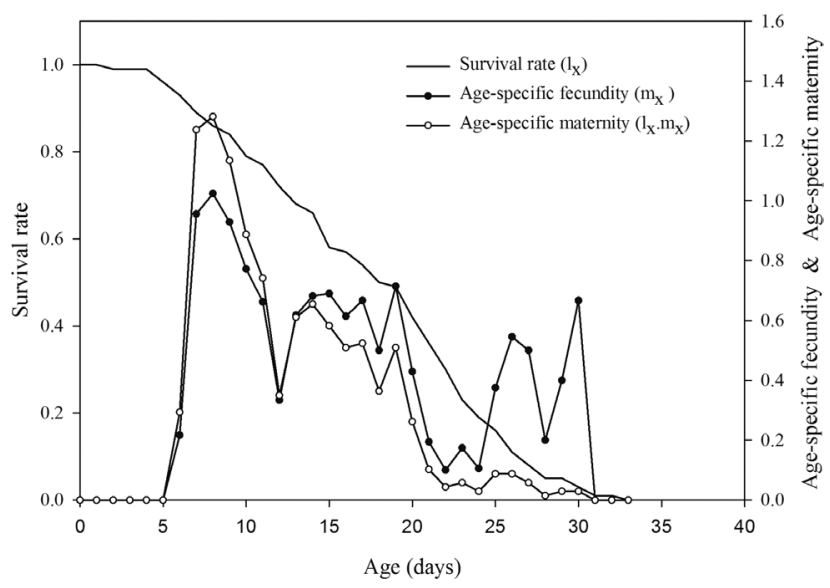

Fig. 2. Trends in the age-stage survival rate $\left(1_{x}\right)$, age-specific fecundity $\left(\mathrm{m}_{\mathrm{x}}\right)$ and maternity $\left(1_{\mathrm{x}} \cdot \mathrm{m}_{\mathrm{x}}\right)$ rate of Diuraphis noxia reared on Sardari, a susceptible cultivar of wheat.

dant stage followed by first instar nymphs. As the different stages of $D$. noxia have different developmental rates (Fig. 3) there are overlaps in the survival rate curves. This point is ignored in analyses using female-based life tables. In addition, Fig. 3 indicates that the survival rates of all life stages were highest on the susceptible cultivar. Reproductive value, defined as the expected relative contribution of an individual to future population numbers, maximally occurred at an age of 11 days on the resistant and 7 days on the susceptible cultivar.

\section{Population parameters of $\boldsymbol{H}$. variegata}

The initial number of lady beetle eggs used in the life table study were 107 and 113 for those reared on aphids collected from susceptible and resistant cultivars of wheat, respectively, of which 90 and 79 reached the adult stage (84\% and 69\% survival rates, respectively). Life history parameters of $H$. variegata reared on aphids collected from the resistant and susceptible cultivars of wheat are presented in Table 3. Values of $r_{m}$ (Mann-Whitney test, U Statistic $=0.00, \mathrm{P}$-value $<0.001), \lambda$ (Mann-Whitney test, U Statistic $=0.00, \mathrm{P}$-value $<0.001), \mathrm{R}_{0}$ (Mann-Whitney test, U Statistic $=2682.0$, P-value $<0.001), \mathrm{T}$ (Mann-Whitney test, $\mathrm{U}$ Statistic $=135.5$, P-value $<0.001)$ and GRR (Mann-Whitney test, U Statistic $=81474.00$, P-value $<0.001)$ differed for ladybirds reared on the resistant and susceptible cultivars of wheat. The trends in age-specific survival curves $\left(1_{x}\right)$, age-specific fecundity $\left(m_{x}\right)$ and age-specific maternity $\left(1_{x} \cdot m_{x}\right)$ of $H$. variegata reared on aphids collected from the resistant and susceptible cultivars of wheat are illustrated in Fig. 4. These figures indicate that $H$. variegata reared

TABle 3. Population parameters (mean \pm SE) of Hippodamia variegata fed on Diuraphis noxia reared on Sardari, a susceptible and Omid, a resistant cultivar of wheat. Symbols in Table1.

\begin{tabular}{lcc}
\hline Parameter & Omid & Sardari \\
\hline $\mathrm{r}_{\mathrm{m}}\left(\mathrm{d}^{-1}\right)$ & $0.24 \pm 0.01$ & $0.20 \pm 0.01$ \\
$\mathrm{R}_{0}$ (offspring) & $399.35 \pm 53.01$ & $221.56 \pm 34.68$ \\
$\lambda\left(\mathrm{d}^{-1}\right)$ & $1.27 \pm 0.01$ & $1.23 \pm 0.01$ \\
$\mathrm{~T}$ (day) & $24.67 \pm 0.28$ & $26.50 \pm 0.41$ \\
GRR (offspring) & $544.23 \pm 75.86$ & $402.72 \pm 67.55$ \\
\hline
\end{tabular}



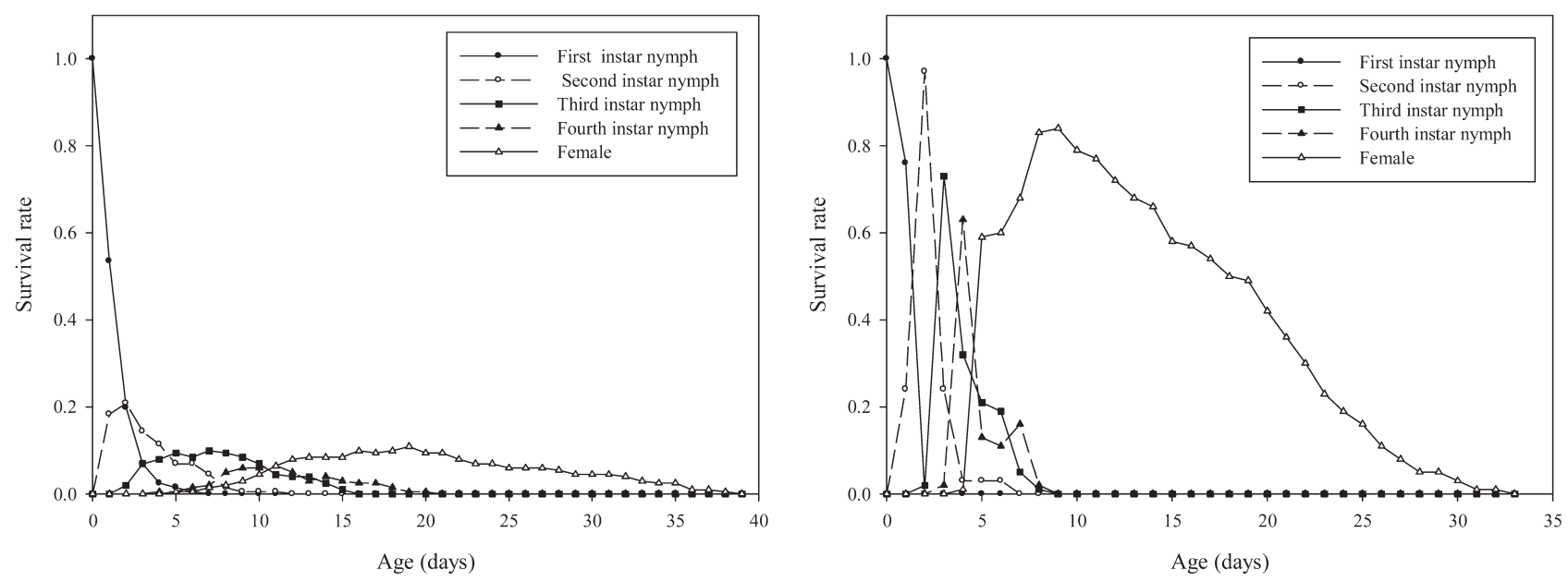

Fig. 3. Survival rate of each age-stage of $D$. noxia reared on the resistant Omid (left) and susceptible Sardari (right) cultivars of wheat.

on aphids collected from the susceptible cultivar of wheat started laying eggs on day 17 and ceased on day 85 (68 days), while those reared on aphids collected from the resistant cultivar of wheat started laying eggs on day 16 and ceased on day 63 (47 days). However, the oscillations in the age-specific fecundity recorded for $H$. variegata fed RWA reared on the resistant cultivar were greater than for those fed RWA reared on the susceptible cultivar (Fig. 4).

Plant resistance affected maximum daily and maximum total fecundity of $H$. variegata with 142 and 125 eggs, and 1716 and 1480 eggs for lady beetles fed $D$. noxia reared on the resistant and susceptible cultivars of wheat, respectively. Maximum reproductive values of $H$. variegata fed $D$. noxia reared on the resistant and susceptible cultivars of wheat were 101.63 and 79.29, which were recorded when they were 18 and 21 days old, respectively. Survival curves of $H$. variegata recorded over the complete developmental period when fed aphids reared on both cultivars of wheat were similar (Fig. 5). The overlapping curves reflect the different developmental rates of the different stages.

\section{Stable age distribution of $\boldsymbol{H}$. variegata}

The stable age distributions of $H$. variegata fed RWA reared on both cultivars of wheat are shown in Table 4 . The stable age distribution of $H$. variegata in both cases are similar, with more than half of the lady beetle population made up of eggs and third instar larvae the least abundant of the larval stages.

\section{DISCUSSION}

This tritrophic study confirmed that the nutritional quality of a host plant affects both the herbivore that feeds on it and its natural enemy. The lower values of life table parameters $\left(\mathrm{r}_{\mathrm{m}}, \mathrm{R}_{0}\right.$ and $\left.\lambda\right)$ recorded for RWA reared on the resistant cultivar of wheat demonstrate the effectiveness of plant resistance against RWA. When reared on the resistant cultivar the intrinsic rate of increase $\left(\mathrm{r}_{\mathrm{m}}\right)$ of RWA was negative (i.e. the population decreased). This might be due to higher immature mortality or reduced fecundity. The age-stage survival rate $\left(1_{x}\right)$ curve indicates that more than half of the nymphs died before reaching the second instar when reared on the resistant cultivar. In addition, the net reproductive rate $\left(\mathrm{R}_{0}\right)$ and the finite rate of increase $(\lambda)$ of $D$. noxia were similarly dependent on the cultivar of wheat they were reared on. Furthermore, on the resistant wheat cultivar the developmental period and mean generation time (T) of $D$. noxia were longer. This effect has consequences in terms of the temporal availability of aphids for natural enemies.
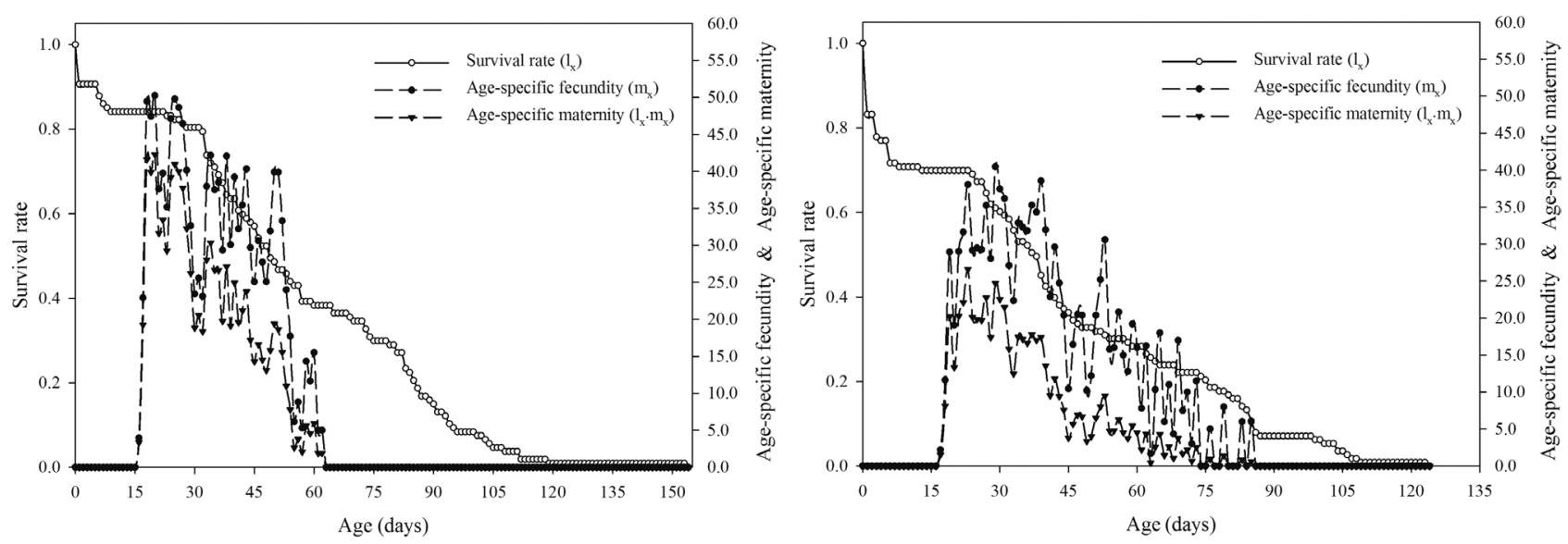

Fig. 4. Trends in the age specific survival $\left(1_{x}\right)$, age-specific fecundity $\left(\mathrm{m}_{\mathrm{x}}\right)$ and maternity $\left(1_{\mathrm{x}} \cdot \mathrm{m}_{\mathrm{x}}\right)$ of Hippodamia variegata fed on Russian wheat aphids reared on Omid (R, left) and Sardari (S, right) cultivars of wheat. 

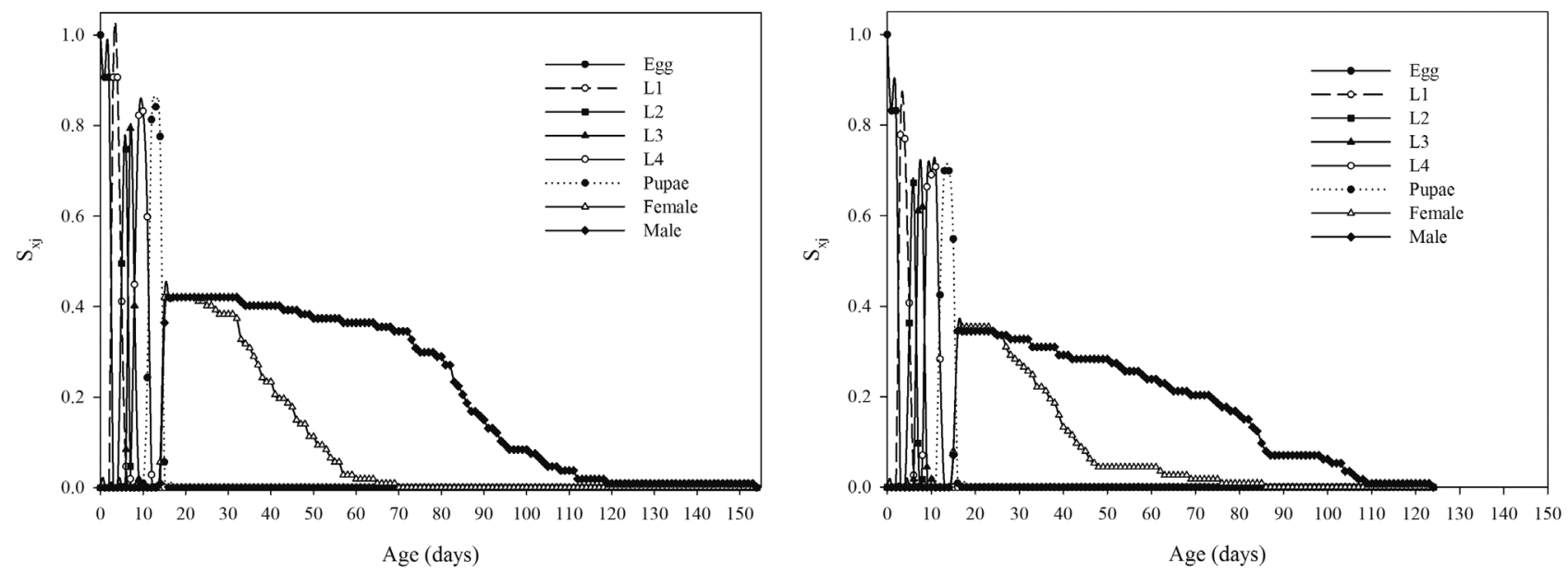

Fig. 5. Survival rate of each age-stage of Hippodamia variegata fed on Russian wheat aphids reared on Omid (R, left) and Sardari (S, right) cultivars of wheat.

As developmental time increases, the chances of natural enemies finding and killing an aphid increases.

A study of the resistance of five cultivars of wheat: Alamoot, Alvand, Zarrin, Sabalan and Sardari, to RWA under field conditions in Tabriz, northwest of Iran, indicates that the greatest and the lowest numbers of progeny produced / female over the first 10 and 15 days of reproduction, respectively, are $34.94 \pm 5.91$ and $48.56 \pm 7.66$ on Sardari and $24.83 \pm 9.36$ and $36.67 \pm 13.67$ on Alvand (Kazemi et al., 2001). Moreover, the highest $r_{m}$ values recorded within 10 and 15 days were $0.268 \pm 0.02$ day $^{-1}$ and $0.264 \pm 0.02$ day $^{-1}$, respectively for individuals reared on Sardari and the lowest, $0.217 \pm 0.03$ day $^{-1}$ and $0.223 \pm 0.03$ day $^{-1}$ on Alvand. Effects of different temperatures and different barley plant growth stages on life table parameters of RWA are reported by Ma \& Bechinski (2009) who record the highest intrinsic rate of increase as 0.288 day $^{-1}$ at $25.08^{\circ} \mathrm{C}$ on stage 12 (Zadoks scale). Veisi et al. (2012) record total fecundities of $61.75 \pm 7.93$ and $24.00 \pm 0.81$, and mean offspring produced per female per day of $2.51 \pm 0.43$ and $1.40 \pm 0.19$ on the cultivars Yavarus and Omid, respectively. Overall, they conclude that Yavarus is susceptible and Omid resistant to RWA.

The most striking finding of our study is that plant quality positively affects the life history parameters of $H$. variegata. Based on the $\mathrm{r}_{\mathrm{m}}$ and other demographic parameters of $H$. variegata, the resistance of wheat to $D$. noxia did not negatively affect the growth, survival and fecundity, and improved the population growth of $H$. variegata. That is, $H$. variegata grew faster and laid more eggs when feed on RWA reared on a resistant than on an aphid-susceptible cultivar of wheat. This dual effect of host plant resistance may be of chemical origin. Natural secondary plant me-

TABLE 4. Stable age distributions (\%) of populations of Hippodamia variegata fed on aphids reared on Sadari, a susceptible and Omid, a resistant cultivar of wheat.

\begin{tabular}{ccccccccc}
\hline Cultivar & Egg & $\mathrm{L}_{1}$ & $\mathrm{~L}_{2}$ & $\mathrm{~L}_{3}$ & $\mathrm{~L}_{4}$ & Pupae & Female & Male \\
\hline Omid & 53.48 & 21.55 & 7.78 & 5.30 & 6.53 & 2.95 & 1.24 & 1.18 \\
Sardari & 50.69 & 20.90 & 8.08 & 6.42 & 7.04 & 3.47 & 1.70 & 1.69 \\
\hline
\end{tabular}

tabolites of the resistant cultivar might have had adverse effects on RWA but when metabolized by the aphid have a positive effect on the reproduction and survival of $H$. variegata relative to that recorded when fed the aphid reared on a susceptible cultivar that lacks these metabolites (Barkhordar et al., 2013). In addition, it is possible these differences are a consequence of differences for $H$. variegata in the digestibility of RWA reared on resistant and susceptible cultivars (Barkhordar et al., 2013).

The life history of $H$. variegata reared at different temperatures and on different diets is well studied. Differences are reported in the demographic parameters of $H$. variegata fed on different species of aphids. El Hag \& Zaitoon (1996) compare four species of coccinellids in terms of their biological parameters and report an $\mathrm{r}_{\mathrm{m}}$ value of 0.082 day $^{-1}$ for $H$. variegata. Mollashahi et al. (2004) studied population growth parameters of $H$. variegata fed on Aphis gossypii Glover and report that the intrinsic rate of increase $\left(\mathrm{r}_{\mathrm{m}}\right)$ and net reproductive rate $\left(\mathrm{R}_{0}\right)$ of this predator are 0.254 day $^{-1}$ and 387.9 eggs, respectively. Lanzoni et al. (2004) report an intrinsic rate of increase of 0.114 day $^{-1}$ for $H$. variegata, which is higher than that of Harmonia axyridis (Pallas) and Adalia bipunctata (L.) fed on Myzus persicae (Sulzer). Farhadi et al. (2011) report an $r_{m}$ value of $0.203 \pm$ 0.005 day $^{-1}$ for $H$. variegata fed bean aphids, Aphis fabae Scopoli, which is similar to the value recorded in this study for $H$. variegata fed on RWA reared on the susceptible cultivar of wheat. In addition, parameters other than $\mathrm{R}_{0}$ have similar values. The $\mathrm{r}_{\mathrm{m}}$ of $H$. variegata fed on $A$. gossypii is $0.179 \pm 0.005$ day $^{-1}$ (Bigdelou, 2012).

Our results indicate that not only the type of prey but also the quality of the host plant of the prey can have substantial indirect effects on the life table parameters and effectiveness of ladybirds. This is also reported for other predatorprey systems (Ofuya, 1995; Wu et al., 2010). Farid et al. (1997) report that the percentage mortality of Scymnus frontalis (Fabricius, 1787) (Coleoptera: Coccinellidae) larvae is higher on susceptible than on RWA-resistant plants and attribute this to the greater incidence of entrapment of $D$. noxia by curled leaves of susceptible cultivars of wheat. 
Cultivar resistance did not affect the weight of the larvae, prepupae, pupae and adults or the total developmental time of $S$. frontalis. Different results are reported by Brewer et al. (1998) who show that use of barley resistant to RWA results in a decrease in the abundance of Diaeretiella rapae (Mc Intosh) and Aphelinus albipodus Hayat \& Fatima as aphid abundance decreases, even though parasitism rates were expected to be approximately equal on resistant and susceptible barley. Farid et al. (1998) report that although the rate of population increase of $D$. noxia is lower on a resistant cultivar of wheat over a period of three generations, plant resistance did not have a negative effect on percentage emergence, sex ratio, adult longevity, or head width of $D$. rapae. Furthermore, when parasitoids emerge from aphids reared on resistant cultivars the longevity of females is greater. Thus, host plant resistance can affect both growth and development of $D$. rapae. The abundance of $D$. noxia on resistant barley lines is lower than on more susceptible lines (Brewer et al., 1998). In addition, the abundance of the parasitoids D. rapae, A. albipodus and Aphelinus asychis Walker, 1839 on resistant and susceptible barley lines is similar (Brewer et al., 1999). They also conclude that in this system, the use of plant resistance and natural enemies are compatible strategies.

The larvae of the lacewing Chrysoperla plorabunda (Fitch) cause a greater proportional reduction in the abundance of RWA on resistant than on near isogenic susceptible lines of wheat, which indicates that lacewings are more effective on resistant plants (Messina \& Sorenson, 2001). The smaller aphid populations or smaller size of individual prey on resistant cultivars may in this case be the cause of the increase in predator effectiveness (Messina $\&$ Sorenson, 2001). Only the larvae of lacewings prey on aphids and therefore they are less exposed to the defensive chemicals of resistant plants. In spring wheat fields in Moscow, Idaho there is no interaction between plant resistance and the population densities of predators and parasitoids (Bosque-Perez et al., 2002). Thus, D. noxia resistant lines do not have any adverse effects on the natural enemies (parasitoids and predators) of D. noxia. However, other studies have demonstrated negative effects of Bt-crops and resistant varieties on parasitoid and predator biology and fecundity (Schuler et al., 1999).

The current study highlights the effect of plant resistance on the 3rd trophic level. If the positive effect of resistant cultivars on $H$. variegata is shown to occur in the field then the release of a fixed number of $H$. variegata should decrease prey abundance even in the lower populations recorded on resistant cultivars (Messina \& Sorenson, 2001). These results increase our understanding of the effects of host resistance on natural enemy biology and if relevant to field conditions, the possibility of important interactions in IPM programs. A biocontrol agent, especially a parasitoid would be more effective if it had a higher $r_{m}$ than its host. In the present study, the ladybird beetles reared on two different types of prey had higher rates of increase than RWA, which indicates that $H$. variegata is a suitable candidate for release against RWA, especially on resistant cultivars of wheat. It is probable that application of this predator on a resistant cultivar might lead to a greater synergistic effect in RWA population. However, it is unclear if this effect is chemically mediated and if so, what the biochemical basis for it is.

ACKNOWLEDGEMENTS. We are grateful to M. Sameni and T. Behnazar for their cooperation. Special thanks to F. Shirzadi for editing an early draft of the manuscript. This study was funded by the Faculty of Agriculture, Bu-Ali Sina University, Hamedan, Iran and formed a part of the M.Sc. thesis of the first author.

\section{REFERENCES}

Atlihan R. \& Chi H. 2008: Temperature-dependent development and demography of Scymnus subvillosus (Coleoptera: Coccinellidae) reared on Hyalopterus pruni (Homoptera: Aphididae). - J. Econ. Entomol. 101: 325-333.

Barkhordar B., Khalghani J., Salehi Jouzani G., Nouri Ganbalani G., Shojai M., Boustani M.T., Karimi E., Soheilivand S. \& Hosseini B. 2013: Impact of host plant resistance on the tritrophic interactions between wheat genotypes, Schizaphis graminum (Homoptera: Aphididae), and Coccinella septempunctata (Coleoptera: Coccinellidae) using molecular methods. - Environ. Entomol. 42: 1118-1122.

Bigdelou B. 2012: Life Table and Predation Capacity of Hippodamia variegata (Col.: Coccinellidae) Feeding on Aphis gossypii (Hem.: Aphididae). MSc. Thesis, University of Tehran, $97 \mathrm{pp}$.

Bosque-Perez N.A., Johnson J.B. Schotzko D.J. \& Unger L. 2002: Species diversity, abundance, and phenology of aphid natural enemies on spring wheats resistant and susceptible to Russian wheat aphid. - BioControl 47: 667-684.

Bottrell D.G., Barbosa P. \& Gould F. 1998: Manipulating natural enemies by plant variety selection and modification: a realistic strategy? - Annu. Rev. Entomol. 43: 347-367.

Brewer M.J., Struttmann J.M. \& Mornhinweg D.W. 1998: Aphelinus albipodus (Hymenoptera: Aphelinidae) and Diaeretiella rapae (Hymenoptera: Braconidae) parasitism on Diuraphis noxia (Homoptera: Aphididae) infesting barley plants differing in plant resistance to aphids. - Biol. Contr. 11: 255-261.

Brewer M.J., Dolores W.M. \& Huzurbazar S. 1999: Compatibility of insect management strategies: Diuraphis noxia abundance on susceptible and resistant barley in the presence of parasitoids. - BioControl 43: 479-491.

CARey J.R. 1993: Applied Demography for Biologists. Oxford University Press, New York, 206 pp.

CHI H. 1988: Life table analysis incorporating both sexes and variable developmental rates among individuals. - Environ. Entomol. 17: 26-34.

Chi H. \& LiU H. 1985: Two new methods for the study of insect population ecology. - Bull. Inst. Zool. Acad. Sin. (Taipei) 24: 225-240.

ChI H. \& YANG T.C. 2003: Two-sex life table and predation rate of Propylaea japonica Thunberg (Coleoptera: Coccinellidae) fed on Myzus persicae (Sulzer) (Homoptera: Aphididae). — Environ. Entomol. 32: 327-333.

Clark T.L. \& Messina F.J. 1998: Foraging behavior of lacewing larvae (Neuroptera: Chrysopidae) on plants with divergent architectures. - J. Insect Behav. 11: 303-317.

Cortesero A.M., Stapel J.O. \& Lewis W.J. 2000: Underestanding and manipulating plant attributes to enhance biological control. -Biol. Contr. 17: 35-49.

Damsteegt V.D., Gildow F.E., Hewings A.D. \& Carroll T.W. 1992: Clone of the Russian wheat aphid (Diuraphis noxia) as a 
vector of barley yellow dwarf, barley stripe mosaic, and brome mosaic viruses. - Plant Dis. 76: 1155-1160.

Dogimont C., Bendahmane A., Chovelon V. \& Boissot N. 2010: Host plant resistance to aphids in cultivated crops: Genetic and molecular bases, and interactions with aphid populations. C. R. Biol. 333: 566-573.

Dolati L., Ghareyazie B., Moharramipour S. \& Noori-Daloi M.R. 2004: Evidence for regional diversity and host adaptation in Iranian populations of the Russian wheat aphid. - Entomol. Exp. Appl. 114: 171-180.

Du TolT F. 1987: Resistance in wheat (Triticum aestivum) to Diuraphis noxia (Hemiptera: Aphididae). — Cereal Res. Commun. 15: $175-179$.

Efron B. \& Tibshirani R.J. 1993: An Introduction to the Bootstrap. Chapman and Hall, New York, 436 pp.

El Hag E.T.A. \& Zaitoon A.A. 1996: Biological parameters for four coccinellid species in central Saudi Arabia. - Biol. Contr. 7: 316-319.

Farhadi R., Allahyari H. \& Chi H. 2011: Life table and predation capacity of Hippodamia variegata (Coleoptera: Coccinellidae) feeding on Aphis fabae (Hemiptera: Aphididae). — Biol. Contr. 59: 83-89.

FARID A., JoHnSON J.B. \& QuisenBerRy S.S. 1997: Compatibility of a coccinellid predator with a Russian wheat aphid resistant wheat. - J. Kans. Entomol. Soc. 70: 114-119.

Farid A., Johnson J.B. Shafil B. \& Quisenberry S.S. 1998: Tritrophic studies of Russian wheat aphid, a parasitoid, and resistant and susceptible wheat over three parasitoid generations. - Biol. Contr. 12: 1-6.

Franzmann B.A. 2002: Hippodamia variegata (Goeze) (Coleoptera: Coccinellidae), a predacious ladybird new in Australia. - Aust. J. Entomol. 41: 375-377.

Gabre R.M., Adham F.K. \& Chi H. 2005: Life table of Chrysomya megacephala (Fabricius) (Diptera: Calliphoridae). Acta Oecol. 27: 179-183.

Golizadeh A. \& Jafari-Beht V. 2012: Biological traits and life table parameters of variegated lady beetle, Hippodamia variegata (Coleoptera: Coccinellidae) on three aphid species. Appl. Entomol. Zool. 47: 199-205.

Gutsche A.R., Heng-Moss T.M., Higley L.G., Sarath G. \& Mornhinweg D.W. 2009: Physiological responses of resistant and susceptible barley, Hordeum vulgare to the Russian wheat aphid, Diuraphis noxia (Kurdjumov, 1913). - Arthrop. Plant Interact. 3: 233-240.

He J., Gao H., Cao Z., Monika W. \& Zhao H. 2013: Life table analysis of the performance of aphid Sitobion avenae (Homoptera: Aphididae) nymphs exposed to a static magnetic field. - Arch. Biol. Sci. (Belgrade) 65: 1415-1422.

Hu Z., Zhao H. \& Thieme T. 2014: Comparison of the potential rate of population increase of brown and green color morphs of Sitobion avenae (Homoptera: Aphididae) on barley infected and uninfected with Barley yellow dwarf virus. - Insect Sci. 21: $326-333$.

HuANG Y.B. \& CHI H. 2011: Age-stage, two sex life tables of Bactrocera cucurbitae (Coquillett) (Diptera: Tephritidae) with a discussion on the problem of applying female age-specific life tables to insect populations. - Insect Sci. 19: 263-273.

Hughes R.D. \& MaYwald G.F. 1990: Forecasting the favorableness of the Australian environment for the Russian wheat aphid, Diuraphis noxia and its potential impact on Australian wheat yields. - Bull. Entomol. Res. 80: 165-175.

JHA R.K., CHI H. \& TANG L.C. 2012: Life table of Helicoverpa armigera (Hubner) (Lepidoptera: Noctuidae) with a discussion on Jackknife vs. Bootstrap techniques and variations on the Euler-Lotka equation. - Form. Entomol. 32: 355-375.
Jimoh M.A., Kaehler S. \& Botha C.E.J. 2013: Increased feeding damage under elevated $\mathrm{CO}_{2}$ : the case of the Russian wheat aphid. - Sth. Afr. J. Bot. 84: 30-37.

Kazemi M.H., Mashhadi Jafarloo M., Talebi Chaichi P. \& ShaKIBA M.R. 2001: Biological responses of Russian Wheat Aphid, Diuraphis noxia (Kurdjumov, 1913) to certain wheat cultivars at emergence stage. - J. Agric. Sci. Technol. 3: 249-255.

Kindler S.D. \& Hammon R.W. 1996: Comparison of host suitability of western wheat aphid with the Russian wheat aphid. - J. Econ. Entomol. 89: 1621-1630.

Kontodimas D.C. \& Stathas G.J. 2005: Phenology, fecundity and life table parameters of the predator Hippodamia variegata reared on Dysaphis crataegi. - BioControl 50: 223-233.

Lanzoni A., Accinelli G., Bazzocchi G.G. \& Burgio G. 2004: Biological traits and life table of the exotic Harmonia axyridis compared with Hippodamia variegata, and Adalia bipunctata (Col., Coccinellidae). - J. Appl. Entomol. 128: 298-306.

MA Z. \& Bechinski E.J. 2009: Life tables and demographic statistics of Russian wheat aphid (Hemiptera: Aphididae) reared at different temperatures and on different host plant growth stages. - Eur. J. Entomol. 106: 205-210.

Macedo T.B., Higley L.G. \& Ni X. 2003: Light activation of Russian wheat aphid-elicited physiological responses in susceptible wheat. - J. Econ. Entomol. 96: 194-201.

Messina F.J. \& SoREnson S.M. 2001: Effectiveness of lacewing larvae in reducing Russian wheat aphid populations on susceptible and resistant wheat. - Biol. Contr. 21: 19-26.

Mollashahi M., Sahragard A. \& Hossaini R. 2004: Determination of life table parameters of lady beetle, Hippodamia variegata (Col: Coccinellidae) under laboratory conditions. $-J$. Agric. Sci. 1: 47-60 [in Persian, English abstr.].

Najafi Mirak T., Zali A., Hosseinzadeh A., Saidi A., Rasoulian G. \& ZeInaLi H. 2004: Inheritance and allelism of resistance to Russian wheat aphid, Diuraphis noxia (Mordvilko) in Iranian wheat cultivars. - Int. J. Agric. Biol. 6: 525-528.

OfuYA T.I. 1995: Colonization and control of Aphis craccivora Koch (Homoptera: Aphididae) by coccinellid predators in some resistant and susceptible cowpea in Nigeria. $-J$. Crop Prot. 14: 47-50.

Qing Nian C., Xiao M.M., Zhao X., Zhong Y.C. \& Yang X.Q. 2009: Effects of host plant resistance on insect pests and its parasitoid: A case study of wheat-aphid-parasitoid system. Biol. Contr. 49: 134-138.

Reed D.K., Webster J.A., Jones B.G. \& Burd J.D. 1991: Tritrophic relationships of Russian wheat aphid (Homoptera: Aphididae), a hymenopterous parasitoid (Diaeretiella rapae McIntosh), and resistant and susceptible small grains. - Biol. Contr. 1: 35-41.

Schuler T.H., Poppy G.M., Kerry B.R. \& Denholm I. 1999: Potential side effects of insect-resistant transgenic plants on arthropod natural enemies. - Trends Biotechnol. 17: 210- 216.

Veisi R., SAfavi S.A. \& Karimpour Y. 2012: Duration of life stages and fecundity of Diuraphis noxia (Hemiptera: Aphididae) on six wheat cultivars. - J. Crop Prot. 3: 181-187.

Wu X., Zhou X. \& Pang B. 2010: Influence of five host plants of Aphis gossypii Glover on some population parameters of Hippodamia variegata (Goeze). - J. Pest Sci. 83: 77-83.

Zu J.Z., Chi H. \& Chen B.H. 2005: Life table and predation of Lemnia biplagiata (Coleoptera: Coccinellidae) fed on Aphis gossypii (Homoptera: Aphididae) with a proof on relationship among gross reproduction rate, net reproduction rate, and preadult survivorship. - Ann. Entomol. Soc. Am. 98: 475-482.

Received June 16, 2014; revised and accepted February 12, 2015 Prepublished online March 20, 2015 